\title{
Erratum to: Improving non-invasive genotyping in capercaillie (Tetrao urogallus): redesigning sexing and microsatellite primers to increase efficiency on faeces samples
}

Trinidad Pérez • José Fernando Vázquez •

Francisco Quirós · Ana Domínguez

Published online: 3 July 2012

(C) Springer Science+Business Media B.V. 2012

Erratum to: Conservation Genet Resour (2011) 3:483-487

DOI 10.1007/s12686-011-9385-8

Unfortunately, in the original publication of the article, the sequences of most of the internal primers listed in Table 1 are incorrectly placed. The author apologizes for this error. The correct Table 1 is provided below.

The online version of the original article can be found under doi: $10.1007 / \mathrm{s} 12686-011-9385-8$.

T. Pérez $(\bowtie)$ · J. F. Vázquez · F. Quirós · A. Domínguez Departamento de Biología Funcional (Genética),

Facultad de Medicina $6^{\circ}$ Planta, Universidad de Oviedo,

C/Julián Clavería s/n, 33071 Oviedo, Spain

e-mail: trinioviedo@ hotmail.com 


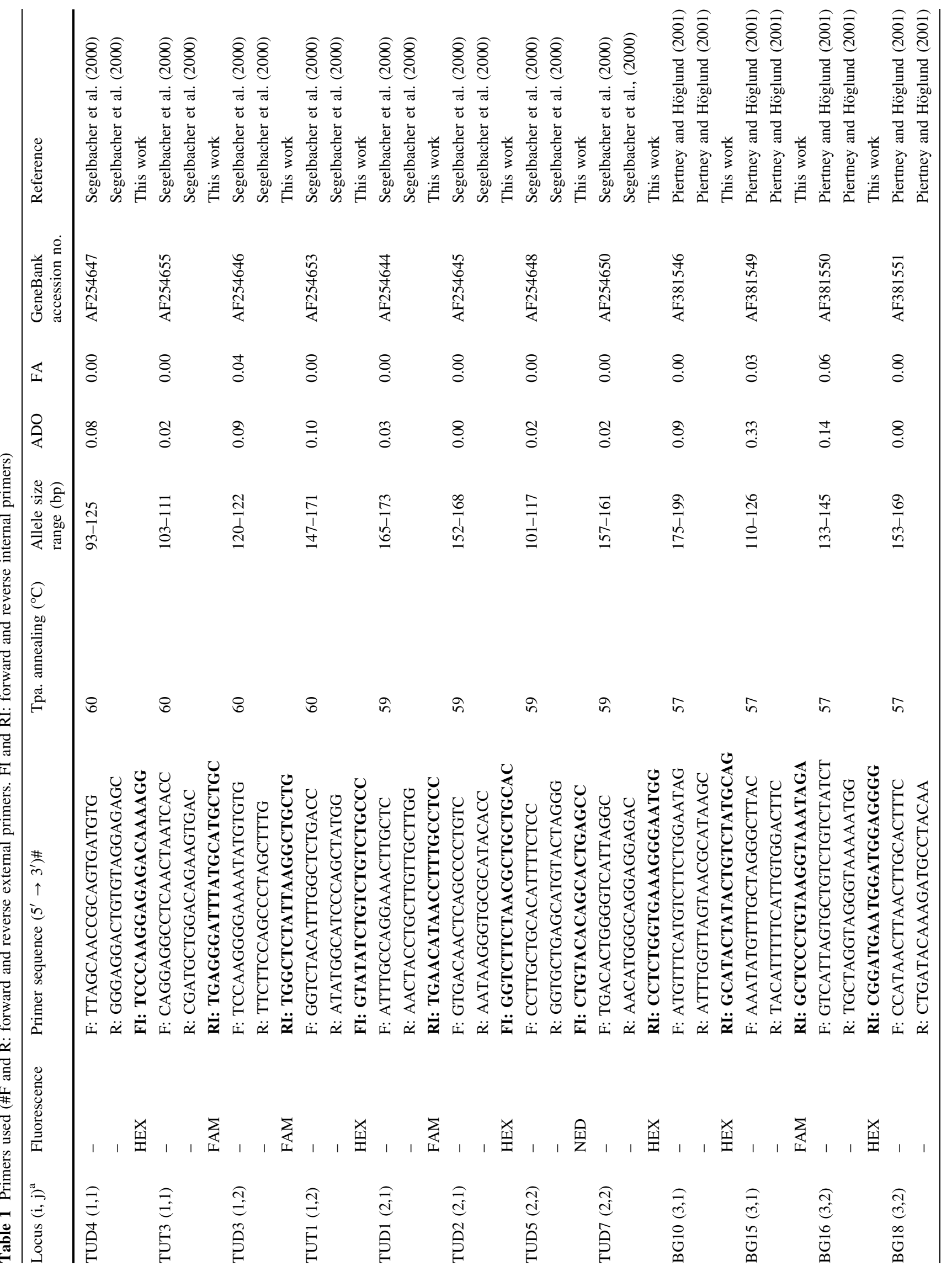




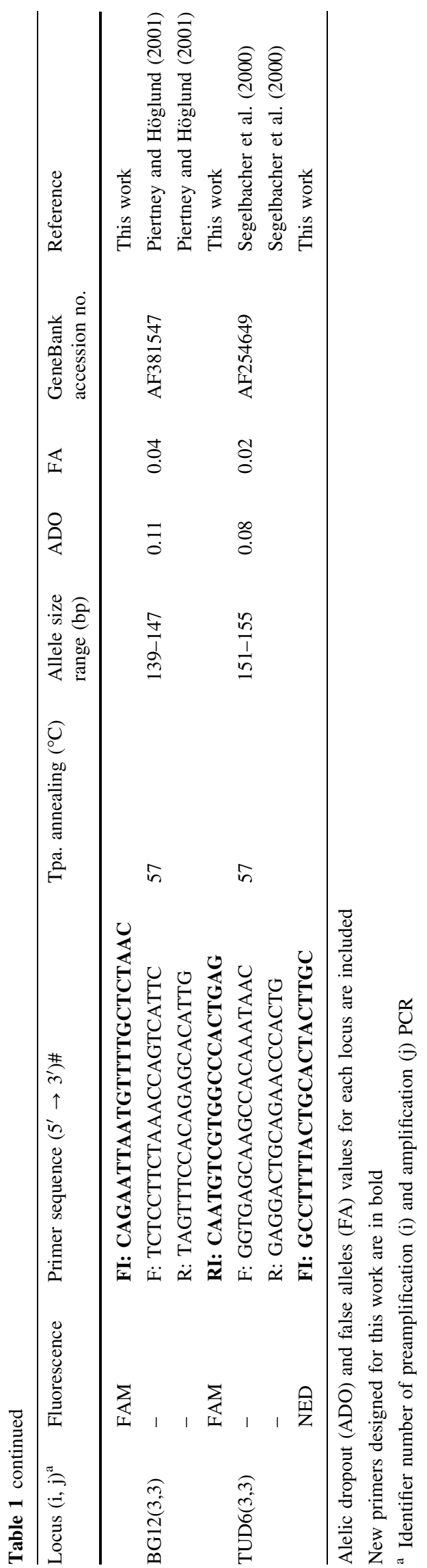

